Research in African Literatures is a journal devoted to the publication of peer-reviewed articles focusing on all aspects of the literatures of Africa, both oral and written. The journal is open to a wide range of critical and theoretical approaches. Additionally, it welcomes articles on topics including, but not limited to, African literatures and other forms of cultural expression, African literatures in an international context, and the relationship between African literatures and those of the metropole and of the recent and historical African diaspora.

Questions should be emailed to reinhoudt.2@osu.edu. Books for review should be mailed to Research in African Literatures, The Ohio State University, 486 University Hall, 230 North Oval Mall, Columbus, $\mathrm{OH} 43210$.

\title{
EDITOR
}

Kwaku Larbi Korang (The Ohio State University)

\section{PAST EDITORS}

Bernth Lindfors, Founding Editor (The University of Texas, Austin, 1970-89)

Richard Bjornson (The Ohio State University, 1990-92)

F. Abiola Irele (The Ohio State University, 1992-2003)

John Conteh-Morgan (The Ohio State University, 2003-08)

\section{ASSOCIATE EDITOR}

Adélékè Adéẹ̀kọ́ (The Ohio State University)

MANAGING EDITOR

Molly Reinhoudt (The Ohio State University)

\section{ADVISORY BOARD}

Susan Z. Andrade (University of Pittsburgh)

Kofi Anyidoho (University of Ghana)

Rita Barnard (University of Pennsylvania)

Carine Bourget (University of Arizona)

Laura Chrisman (University of Washington)

Gaurav Desai (University of Michigan)

Simon Gikandi (Princeton University)

Kenneth W. Harrow (Michigan State University)

Waïl Hassan (University of Illinois, Urbana-Champaign)

Anthonia Kalu (University of California, Riverside)

Catherine Kroll (Sonoma State University)

Ruthmarie H. Mitsch (Managing Editor, RAL, 1989-2012)

Lydie E. Moudileno (University of Pennsylvania)

H. Adlai Murdoch (Tufts University)

Patrice Nganang (Stony Brook University)

Obioma Nnaemeka (Indiana University-Purdue University Indianapolis)

Anjali Prabhu (Wellesley College)

Ato Quayson (Stanford University)

Micheline Rice-Maximin (Swarthmore College) 